\title{
THE PERFORMANCE OF VIRTUAL TEAMS
} An Analysis based on Indicators

\author{
Marina K. Nakayama ${ }^{1}$, Michelle d'Ávila Matoso ${ }^{1} \&$ Ricardo A. Silveira ${ }^{2}$ \\ ${ }^{1}$ Universidade Federal do Rio Grande do Su l-UFRGS ${ }^{2}$ Universidade Federal de Pelotas - \\ UFPEL
}

\begin{abstract}
Virtual teams have recently provided an alternative way of organising work in organizations. The efficient management of virtual teams is a key component of overall organizational management. The objective of the present work is to analyze the performance of two virtual teams. Data collection was based on interviews, surveys, minutes of meetings and observation. This study verified that the support offered to virtual teams was not effective if the particular characteristics of the virtual teams, as well as their complexity, were not taken into account. We highlight the importance of considering success factors in virtual teams: adequate technology, Human Resources policy that offers support to the virtual worker, training of leaders and members, standardized work procedures, and leadership skills.
\end{abstract}

Key words: user groups, virtual learning organization, evaluation/formative

\section{INTRODUCTION}

The working world is changing rapidly, and technological development is a determining factor of this change. Technological change, the advent of the Internet, and new distance communication facilities (e-mail, audio and video conferencing) create new possibilities for teamwork in which people can work together to develop their projects even if they are not in the same physical environment. Virtual teams arise within this context: they are groups of workers, geographically distant, that interact through computerbased communication. As virtual teams are rapidly becoming common workplace realities in organizations, the efficient management of these teams constitutes a key component of an organization's managerial responsibilities. 
The objective of our research is to answer the following question: What are the indicators of a virtual team's performance? In the following sections we discuss some theoretical issues about virtual teams in organizations, the research methodology employed in this work, details of the particular case study examined here, and our findings from a study of two virtual teams.

\section{VIRTUAL TEAMS}

Virtual teams are part of the most recent phase of organizational evolution. In the nomadic era, the formation of small groups marked the first invention of ways of structuring people in organizations. This convention evolved very quickly and people started to organize themselves in cities. A more bureaucratic form of organization was required during the Industrial Revolution. Today, the World is in the information era and another mode of organization has begun to arise: the networked organization (Lipnack \& Stamps, 1999). It is within this new organization that virtual teams are embedded. According to Zimmer (2001):

'Virtual teams are work groups composed of people that interact at distance, in a provisional or permanent way, in a company and/or network of which they take part, and that, using advanced technological devices keep in touch and carry out their tasks, trying to reach common goals.'

This kind of team, as with any other, is a group of people with different opinions and different levels of relationships, guided by an organisational objective. They differ from traditional teams by the fact that they work in different places, time and organizational boundaries.

Duarte \& Snyder (1999) identify the existence of some critical success factors in virtual teams. The factors that affect the probability of a team performing at a high level are technology, human resources policy, training and development for leaders and team members, organization and team process patterns, organizational culture, leadership, and leader and member competency. Duarte \& Snyder (1999) have identified the following seven types of virtual teams:

1. Network teams: those with a capacity for aggregating members who are not from the same organization, such as participants of the clients or suppliers' network, or even autonomous experts. For instance, contracting an expert on aeronautics to take part in the development of a new aircraft model for a virtual team of an aircraft building company.

2. Parallel teams: those that 'carry out missions, tasks or special missions that the organization does not want or is not equipped enough to perform' 
(Duarte \& Snyder, 1999, p.6). Normally their action is for a short period and they aim at suggesting improvements of internal processes or specific business issues.

3. Project or product development teams: they are intended to develop new products and organizational processes or, moreover, the creation of information systems, not used for routine tasks. These teams have higher life cycles, besides the possibility of implementing their decisions and not only suggesting recommendations.

4. Work or production teams: applicable to the routine and ongoing works that often affects a department.

5. Service teams: to carry out services for clients—such as consulting.

6. Management teams: composed of 'moving' business people who meet through a video or audio conferences to discuss and make decisions. In these teams, members are part of the same organization.

7. Action teams: used with the aim of 'offering immediate answers, often in emergency situations' (Duarte \& Snyder, 1999, p.8).

We verified that both employees and employers value the advantages of virtual teams. Employees benefit because they save the time that was once spent going to other company units to take part in meetings, and thus they have more time to do their work. However, organizations must be prepared to implement and maintain the necessary technology for teamwork to function effectively. It is also necessary that organizations provide adequate training and support in the effective use of communication and collaborative technologies.

Employees need to have discipline and work in different schedules. They need to know how to use the available tools, and must be aware of the difficulties that the lack of physical contact may bring to their participation in virtual teams: possible communication noises, lack of motivation or even of confidence.

\section{RESEARCH METHODOLOGY}

This work used a qualitative case study methodology. The methods used for data collection included interviews, surveys sent by e-mail, analysis of email messages and direct observation of developed works. In addition there were a number of meetings to discuss the research goals. All members from both teams collaborated with our research. The company research was carried out was at Effen Brasil, a North-American company which represents food products in Brazil. 


\section{EFFEM BRASIL VIRTUAL TEAMS: HISTORY AND OPERATION}

Based on our observations and interviews, the following reports on the history and operations of the Alfa and Beta virtual teams from Effem Brasil.

\subsection{The Alfa team}

The Alfa team has been operational since November 2001. It consists of 17 members from the units of Eldorado do Sul (Rio Grande do Sul, Brazil) and Mogi Mirin (São Paulo, Brazil). Not all of the participants know each other personally. The objective of this team is to re-launch a well-known company trademark.

The team leader responsible for the trademark in Brazil counts on the support of representatives from all necessary areas, such as business (food products sale), research and development, purchasing, services and finance. Each member has a particular personal role within the team, depending on his or her area of responsibility.

The team is currently undergoing a period of change due to the company's location and its difficulties in achieving sales goals. There are no expectations for deadlines, projects or funding approval. This is because the company is facing a merging period, and projects must wait for directorate approval. According to the team members, this is generating a lack of motivation and commitment. The leader has tried to make all information as transparent as possible to warrant the comprehension and confidence of all team members.

\subsection{The Beta team}

The Beta team has been working for about four years. The team's objective is to strengthen the brands of a certain business segment, and to reach financial goals. The team consists of a group of 15 members from the units of Eldorado do Sul and Recife, in Brazil. Not all team members know each other personally.

The team leader conducts the meetings, and starts by reading the minutes from the last meeting in order to check what has not been solved. Each ongoing project leader presents the current situation of activities.

Team communication is clear and objective: it makes good use of e-mail, telephone and video-conferences. All team decisions and processes are documented and given official status in order to avoid communication problems. 
The Beta team is currently well motivated. Members are interested and there is significant participation. Although the company is in a period of change, apparently this team has not been affected by it. Perhaps this difference in behavior is because this team had great results in the past year, which makes the company interested in developing their projects, releasing funds and approving their projects more rapidly. This way one can realize that the external set has an influence on team performance.

\section{RESULT ANALYSIS AND DISCUSSION}

This section presents the research data and our findings.

\subsection{Results}

This research identified and analyzed possible indicators of the performance of the two virtual teams. Both teams have different realities, and act in different branches and have different goals. The Alfa team is going through a complicated period and the company is re-defining the focus of their work. The Beta team is in a confident phase, in which members are committed and interested, as well as successfully completing their projects.

Members were asked to identify factors that influenced their team's high and low performance, and also to describe other factors that might affect the virtual team's overall work. Factors mentioned as being responsible for the team's high performance included commitment, having clear goals and the team members' motivation. The most cited factors affecting a team's overall virtual work, were adequate communication, leadership and good guidance.

The Alfa team considers that the possible cause of their low performance at this moment is due to the company failing to clearly define what it wants them to accomplish. On the other hand, they also believe that good leadership is a factor that will be responsible for the expected high performance when such definitions are finally set. Moreover, they say that the team is integrated; they all have well defined roles that may help them to perform at a higher level. The Beta team considers their good performance is due to the team's integration, well-defined objectives and to the commitment of all its members.

\subsection{Analysis}

Most of the characteristics and factors that may bring success to a team, besides being very much alike, work well for both the traditional and virtual 
teams. (Drexler,1995; Scholtes, 1992) However, some are more critical in virtual teams than in real-world teams.

The first characteristic is orientation. It is necessary that all members know why they are taking part in a team, and have an understanding of why the team exists. In a virtual team, where there are not many physical or faceto-face links between people, it is essential that one knows what the team's goal is. Therefore, the first point to be set in the process of a team development is to guarantee guidance. In our observations we verified that both teams are well directed about their mission, and why their members were selected to be part of it.

After the first phase is accomplished, another critical characteristic is confidence. It's easier to trust people when they are close and you can see their performance at work, than it is to trust someone that you do not know personally and do not see how they work. Building confidence is essential in a virtual team because working at a distance without rigid control requires people to really believe that their team partners are conscientiously performing their work as previously arranged. Perhaps, due to the fact that the Beta team has already obtained positive results, they are confident about the other members' performance, and their work has become easier.

The third phase is to clarify what the team is attempting to achieve. It is necessary to define the roles and make the objectives very clear; good communication is a critical factor. In a traditional team it is possible to perceive signs of comprehension, and also to observe gestures and expressions. This is not possible in a virtual team. Besides sending a message, it is essential that a virtual team guarantees that the person who is receiving the message understands it. The Beta team worked out this phase very well. Alpha team, however, did not because it did not have its objectives well defined.

Subsequently, it is important to get an explicit commitment from all members about how they will carry out their activities. Such a commitment is a critical factor in a virtual team's success. If the participants do not demonstrate commitment to the tasks and the team, all group activities may be ruined. In a team, each member plays a crucial role; if someone does not accomplish his or her activity, the team's performance may be affected. Clear communication and feedback are essential in this phase.

The fifth phase mentioned is implementation. Who makes what, when and where must be defined in a consensual way. All members must take part actively in this phase in order to keep the commitment with the tasks.

After all these phases are concluded, a team can aim for a high level of performance. However, teams are dynamic and need to be sustained. After a high level of performance, they need to review the factors that led to their 
success. It is important to hold what has been learned and get prepared for a new action cycle.

The first two phases worked out very well for both teams. However, the third phase did not work well for the Alfa team. This suggests that an external scenario has influenced the team-the organization's failure to clearly define the team's specific role in the organizational structure. Despite having addressed items 1 and 2 above, the Alpha team's overall objective is not clear and they will not produce a high performance without one, despite being motivated, oriented, and confident.

\section{DISCUSSION}

Besides the characteristics described above, it is important to consider critical success factors for a virtual team in order to maximise the potential for optimal performance.

- The company should select adequate technology to support the virtual teams. It must make sure that this technology works when it is required, because virtual teams depend on it to develop their projects. In the case of Effem Brasil, this factor is not critical because the company supplies all the necessary technology, such as e-mail, intranet, video-conference, telephone and instant-messaging.

- It is desirable to provide training for the leaders and members of the teams not only in the use of technology, but also in facilitation skills, project management and the use of tools for conducting meetings.

- The team leader has a fundamental role in the good performance of the team. That is why it is important to provide this person with the necessary tools and skills. The leader should have excellent communication skills, set expectations, allocate resources, and model necessary behaviours. The organization we studied has been successful in accomplishing the work in development and formation, not only of the leaders, but also of the individual team members.

From the present study, it is possible to make the above recommendations to the company, leaders and team members. Effem Brasil has more virtual teams than traditional ones in their structure. The company's culture suggests this organizational model, because their members must develop projects with people from other parts of the country. It is necessary that the company starts to consider the characteristics of its virtual teams mentioned in this study in order to make their work easier and to foster better corporate results. 


\section{REFERENCES}

Drexler, S. (1995). Teams'development. San Francisco: Jossey-Bass.

Duarte, D. L., \& Snyder, N. T. (1999). Mastering Virtual Teams: strategies, tools and techniques that succeed. San Francisco: Jossey-Bass.

Lipnack, J., \& Stamps, J. (1999). Virtual teams: the new way to work. Strategy \& Leadership, 17(1), 14-19.

Scholtes, P. R. (1992). Times da Qualidade: como usar equipes para melhorar a qualidade. Rio de Janeiro: Qualitymark.

Zimmer, M. V. (2001) Criação de Conhecimento em Equipes Virtuais: Um Estudo de Caso em Empresa do Setor de Alta Tecnologia. Dissertação. Porto Alegre, Departamento de Ciências Administrativas, UFRGS.

\section{BIOGRAPHY}

Marina Keiko Nakayama is a professor at the Business School at the Universidade Federal do Rio Grande do Sul. Michelle d'Ávila M. Matoso is an undergraduate student at the same univerity. Ricardo Azambuja Silveira is a professor of Computer Science at the Universidade Federal de Pelotas. Their research interests are in the design and use of virtual relationships, e-learning, and distance education in Human Resource Development.

\section{ACKNOWLEDGEMENTS}

This research is supported by grants from the Brazilian research agencies: CAPES Coordenação de Aperfeiçoamento de pessoal de Nível Superior, CNPq - Conselho Nacional de Desenvolvimento Científico e Tecnológico and FAPERGS - Fundação de Amparo a Pesquisa do Rio Grande do Sul. 